UDC 323.1

Submitted: 30.09.2016

LBC 66.(4)2Poc

Accepted: 21.10 .2016

\title{
REUNION OF CRIMEA AND RUSSIA IN THE CONTEXT OF TRENDS AND CONTRADICTIONS OF CONTEMPORARY POLICY-MAKING
}

\author{
Ekaterina G. Kirsanova \\ Lomonosov Moscow State University, Moscow, Russian Federation \\ Sergey A. Pankratov \\ Volgograd State University, Volgograd, Russian Federation
}

\begin{abstract}
The process of reunification of Crimea and the Russian Federation is considered in the context of the content, the basic trends and contradictions of the modern political process at the global, regional and national government levels. Analyzing the reunification of Crimea with Russia, the authors reveal the problem of observing the principle of sovereign equality of the states, territorial integrity, non-interference into the internal affairs of the states, the right of peoples to self-determination. The authors highlight the geopolitical threats and risks arising from the violation of the principle of force non-use or threat of force in the situation of "Ukrainian crisis".

This process is analyzed through the prism of the political history of Russia, the establishment and strengthening of its statehood. Interpreted documentary sources reveal the organizational, legal, and political contradictions of the transfer of Crimean region from the Russian Soviet Federative Socialist Republic to the Ukrainian Soviet Socialist Republic in 1954. Socio-political importance of the reunification of Crimea and the Russian Federation for the present stage of modernization transformations of the society and the state are considered. The possible scenarios of development of the internal political and international situation with regard to the sanctions confrontation of Russia and some foreign countries are analyzed. The authors identified the resources for: effective assertion of the national interests of the Russian Federation; ensuring stability and security of life for all people living on its territory; permanent reproduction of national elite abilities (political, administrative, military, economic, etc.) to act decisively in critical situations, to make fateful decisions of geopolitical nature.

The article uses the results of sociological surveys of public opinion about the attitude of the Russians and citizens of Ukraine to the process of reunification of Crimea with Russia.
\end{abstract}

Key words: Crimea and Sevastopol, Russian Federation, reunion, political process, trends, contradictions, sanctions, social and policy-making.

\section{ВОССОЕДИНЕНИЕ КРЫМА С РОССИЕЙ В КОНТЕКСТЕ ТЕНДЕНЦИЙ И ПРОТИВОРЕЧИЙ РАЗВИТИЯ СОВРЕМЕННОГО ПОЛИТИЧЕСКОГО ПРОЦЕССА}

\author{
Екатерина Геннадьевна Кирсанова
}

Московский государственный университет им. М.В. Ломоносова, г. Москва, Российская Федерация 


\section{Сергей Анатольевич Панкратов}

Волгоградский государственный университет, г. Волгоград, Российская Федерация

Аннотация. Процесс воссоединения Крыма с Российской Федерацией рассматривается в контексте содержания, основных тенденций и противоречий развития современного политического процесса на глобальном, региональном и национально-государственном уровнях. При анализе воссоединения Крыма с Россией раскрываются проблемы соблюдения принципа суверенного равенства государств, территориальной целостности, невмешательства во внутренние дела государств, права народов на самоопределение. Выделены геополитические угрозы и риски, возникающие при нарушении принципа неприменения силы или угрозы силой в ситуации «украинского кризиса».

Интерпретированы документальные источники, раскрывающие организационно-правовую и политическую противоречивость передачи Крымской области из состава РСФСР в состав УССР в 1954 году. Обосновано социально-политическое значение воссоединения Крыма с Российской Федерацией для современного этапа модернизационных преобразований общества и государства. Проанализированы возможные сценарии развития внутриполитической и международной ситуации в связи с санкционным противостоянием России и ряда зарубежных государств. Выявляются ресурсы для эффективного отстаивания национально-государственных интересов Российской Федерации; обеспечения стабильности и безопасности жизнедеятельности всех народов, проживающих на ее территории; постоянного воспроизводства способности отечественной элиты (политической, административной, военной, экономической и др.) решительно действовать в критических ситуациях, принимать судьбоносные решения геополитического характера.

В статье использованы результаты социологических исследований общественного мнения об отношении россиян и граждан Украины к процессу воссоединения Крыма с Российской Федерацией.

Ключевые слова: Крым и Севастополь, Российская Федерация, воссоединение, политический процесс, тенденции, противоречия, санкции, социально-политическое значение.

Каждую историческую эпоху развития человеческого сообщества отличает своя осевая проблема, выражающая основное противоречие. Вторая половина XX в. характеризовалась противостоянием двух мировых (социалистической и капиталистической) систем. Очевидно, что осевой проблемой начала XXI столетия выступает взаимодействие цивилизаций в процессе глобализации мира. Как подчеркнул в своем выступлении на заседании Международного дискуссионного клуба «Валдай» Президент РФ В.В. Путин, «противоречия, связанные с перераспределением экономической мощи и политического влияния, только нарастают, груз взаимного недоверия сужает наши возможности для того, чтобы эффективно отвечать на стоящие перед мировым сообществом реальные вызовы и реальные угрозы. По сути в кризисе оказался сам проект глобализации, а в Европе говорят уже мы это хорошо знаем, слышим - о несостоятельности мультикультурализма» [9].

Сложные и противоречивые политические процессы, разворачивающиеся в современной России и мире в целом, актуализируют перед учеными-политологами и действующими политическими институциональными / не- институциональными акторами задачи, связанные с осмыслением новых реалий, прогнозированием последствий глобальных и региональных трансформаций, с их влиянием на механизмы, темпы, направленность национально-государственного строительства в РФ. При этом сам политический процесс целесообразно понимать как непрерывный «цикл политических изменений, последовательную смену состояний политической системы, фиксирующую уровень и характер политизации социального организма» [11, с. 56].

Вместе с тем, с нашей точки зрения, следует согласиться с позицией И.И. Кузнецова, отмечающего, что «современный политический процесс выглядит во многом как высокоинтенсивная коммуникация. Взаимодействие противников / оппонентов в конфликте многообразно и существует в виде сложных коммуникативных стратегий, сочетающих как прямое давление на оппонента, так и непрямые действия, связанные с распространением дезинформации, формированием негативного образа оппонента и его ценностей, привлечением на свою сторону других участников и / или наблюдателей конфликта» [3, c. 298]. Такая характеристика современного 
политического процесса очень важна для понимания сущности и значения событий, последовавших за тем, как руководство Российского государства поддержало решение населения Крыма и Севастополя на референдуме, проведенном 16 марта 2014 г,, о вхождении в состав Российской Федерации на правах ее полноправных субъектов.

Большинство западных СМИ взяло курс на планомерную дискредитацию России и ее высшего политического руководства, обвиняя в агрессии, нарушении международного права, поддержке экономических и иных (персональных) санкций. При этом используются технологии фальсификации конкретных фактов и событий, пропагандистские клише времен холодной войны. Как отметил В.В. Путин, Россия пытается адекватно реагировать на данные выпады, но у нас не существует такой «пропагандистской машины», которая создана и функционирует на Западе. «У нас нет таких глобальных средств массовой информации, как $\mathrm{CNN}, \mathrm{BBC}$ и некоторые другие, у нас таких возможностей пока нет» [9].

Целый ряд стран, в первую очередь входящих в ЕС, США ввели ограничительные меры непосредственно в отношении Республики Крым и Севастополя: запрет на импорт товаров, за исключением имеющих сертификат происхождения, выпущенный украинскими властями; приостановление инвестиций со стороны европейских физических и юридических лиц; лишение права зарубежным операторам предоставлять туристические услуги, а также запрет круизным лайнерам на остановку в портах Крыма и Севастополя. Запрещается экспорт определенных товаров и технологий в сфере транспорта, телекоммуникаций, энергетики, разведки и добычи нефти, газа и других природных ресурсов [13]. Все эти санкционные меры, безусловно, для конкретных предприятий и населения полуострова создают социально-экономические проблемы, последствия которых растянуты во времени и ложатся дополнительным бременем на российское общество в целом.

При этом следует признать, что геополитическое окружение Российского государства на всем протяжении его многовекового существования всегда было сложным и редко миролюбивым. Ни одна страна не может сравниться с Россией по количеству сопредельных стран, многие из которых часто находились друг с другом во враждебных отношениях. И в настоящее время «расширение НАТО и Евросоюза на восток, экономическая мощь Японии, подъем экономики в Китае, Индии, Южной Корее, демографическая и политическая динамика в Турции и Иране, угрозы, связанные с Пакистаном и Афганистаном, резкая активизация мусульманского мира - все это приводит к тому, что Россия (помимо аморфного пространства СНГ) оказывается окруженной странами, альянсами и союзами, многие из которых превосходят ее по размерам экономики, динамичности, многим компонентам силы и численности населения» [4, с. 562].

Воссоединение Крыма с Россией является логическим продолжением процессов, связанных с распадом СССР и формированием новой государственности в его бывших республиках. Стратегия «Евромайдана», направленная на ускоренную евроинтеграцию, обострение внутриполитической обстановки в Украине в связи с государственным переворотом и фактическим бегством законного президента страны В.Ф. Януковича, введение режима антитеррористической операции, проявляющегося в боевых действиях между новой властью и самопровозглашенными республиками ДНР и ЛНР, указывают, с одной стороны, на вынужденность организации и проведения референдума ради сохранения стабильности и безопасности жизнедеятельности населения Крыма в сложившейся ситуации. С другой стороны, данное развитие событий акцентирует внимание на противоречивости и неоднозначности последствий распада СССР для конкретных народов, исторически связанных с формированием Российского государства, русской культуры и ее ментальных основ.

Выступая в Георгиевском зале Кремля перед депутатами Государственной Думы, членами Совета Федерации, руководителями регионов и представителями гражданского общества, Президент РФ В.В. Путин подчеркнул, что «в Крыму буквально все пронизано нашей общей историей и гордостью. Здесь древний Херсонес, где принял крещение святой князь Владимир. Его духовный подвиг - обращение 
к православию - предопределил общую культурную, ценностную, цивилизационную основу, которая объединяет народы России, Украины и Белоруссии. В Крыму - могилы русских солдат, мужеством которых Крым в 1783 году был взят под российскую державу. Крым - это Севастополь, город-легенда, город великой судьбы, город-крепость и Родина русского черноморского военного флота. Крым - это Балаклава и Керчь, Малахов курган и Сапун-гора. Каждое из этих мест свято для нас, это символы русской воинской славы и невиданной доблести» [6, с. 31-32].

По прошествии более 60 лет с момента принятия решения о передаче Крымской области из состава РСФСР в состав УССР ${ }^{1}$ особенно видны правовой беспредел и волюнтаризм, характерные для социально-политических отношений того периода отечественной истории [12]. Ради справедливости следует отметить, что это решение принималось в знаменательные дни празднования трехсотлетия воссоединения Украины с Россией, по доминирующей в то время версии, в знак укрепления единства и нерушимости дружбы русского и украинского народов. «...По большому счету это решение воспринималось как некая формальность, ведь территории передавались в рамках одной большой страны. Тогда просто невозможно было представить, что Украина и Россия могут быть не вместе, могут быть разными государствами. Но это произошло» [6, с. 33-34].

11 марта 2014 г. Верховная рада Автономной Республики Крым и Севастопольский городской совет приняли Декларацию о независимости Автономной Республики Крым и города Севастополя. В данном документе говорилось, что «в случае волеизьявления народов Крыма будет принято решение о вхождении Крыма, включая Автономную Республику Крым и город Севастополь, в состав России, Крым после референдума будет объявлен независимым и суверенным государством с республиканской формой правления». Голосовавшие за принятие Декларации отметили, что в своем решении исходят «из положений Устава ООН и целого ряда других международных документов, закрепляющих право народов на самоопределение». Более того, депутаты приняли «во внимание подтверждение Международным судом ООН в отношении Косово от 22 июля 2010 г. того факта, что одностороннее провозглашение независимости частью государства не нарушает какие-либо нормы международного права» [7].

16 марта 2014 г. в Крыму состоялся референдум, на который было вынесено два вопpoca: «Вы за воссоединение Крыма с Россией на правах субъекта РФ?» и «Вы за восстановление действия Конституции Республики Крым 1992 года и за статус Крыма как части Украины?» Результаты референдума показали, что без учета севастопольцев в плебисците приняли участие 83,01 \% крымчан, имеющих право голоса, из которых 96,77 \% проголосовали за воссоединение Крыма с Россией. В Севастополе приняли участие в референдуме 96,77 \% жителей, из них ответили за на первый вопрос 95,6 \% человек [10].

Спустя два с половиной года после этого события, на пленарном заседании межрегионального форума Общероссийского народного фронта «Форум действий. Крым» В.В. Путин отметил: «Мы знаем, как много среди крымчан, севастопольцев активных людей, неравнодушных, с активной позицией, искренне болеющих, переживающих за судьбу Крыма, за судьбу России в целом. И самое яркое подтверждение этому, конечно, события весны 2014 года, когда люди сами определили свою судьбу, сами решили, где и как они хотят жить. С того момента была проведена масштабная и трудоемкая работа по интеграции Республики Крым, Севастополя в единое правовое, экономическое, социальное пространство России» [5]. При этом Президент РФ подчеркнул, что, естественно, многие проблемы еще не решены, так как копились годами и десятилетиями. В настоящее время необходимо сосредоточиться на самых болезненных и жизненно важных для граждан вопросах.

Несмотря на объективные трудности адаптации крымчан к российским реалиям, а также недружественную, если не сказать враждебную, деятельность со стороны Украины по отношению к жителям полуострова, санкционные мероприятия ряда зарубежных стран, регулярные замеры общественного мнения фиксируют устойчивость положитель- 
ного восприятия большинством населения процесса воссоединения с РФ. Результаты проведенного в 2015 г. опроса GFK Ukraine по заказу компании Berta Communications при поддержке Canada Fund for Local Initiatives показывают, что подавляющее большинство крымчан - $82 \%$ - поддерживают присоединение полуострова к России, 11 \% опрошенных скорее поддерживают присоединение и лишь 4 \% (34 человека из 800 опрошенных) выступают против [13]. По данным ЛевадаЦентра (опрос проводился в сентябре 2016 г.), более $83 \%$ населения РФ позитивно оценивают факт воссоединения РФ и Крыма, около $13 \%$ скорее отрицательно и $4 \%$ затруднились с ответом [8].

В сентябре 2016 г. на состоявшихся выборах в Государственную Думу Федерального собрания РФ впервые были избраны депутаты от Крыма и Севастополя. Этот факт специально был выделен в приветственном слове В.В. Путина на первом заседании нового созыва Госдумы: «Сегодня в этом зале представители всех 85 субъектов Российской Федерации. И среди них народные избранники из Крыма и Севастополя. Результаты выборной кампании основаны на воле и выборе российского общества. Вижу в безусловной легитимности парламента залог силы и авторитета законодательной власти» [1].

Несмотря на то что представители Украины, США и стран Евросоюза заявили о нелегитимности прошедших выборов в Госдуму РФ на территории Крыма, тем не менее Россия отстаивает свое право на реальный суверенитет в глобализирующемся мире. В рамках современного политического процесса четко прослеживаются попытки отдельных государств, в первую очередь США, на практике реализовать связку глобализация десуверенизация - демократизация через воздействия на внутриполитические процессы иных государств. «Экспорт демократии» осуществляется насильственным путем, в обход решений $\mathrm{OOH}$, путем нарушения действующих норм международного права. Таким образом, суверенитет выступает в настоящее время центральным понятием и инструментальной ценностью в системе международных отношений. «Его уважение, укрепление это залог мира, стабильности и на националь- ном и на международном уровне. Стран, которые, как Россия, могут опереться на тысячелетнюю историю, в мире немало, и мы научились ценить свою идентичность, свободу и независимость. При этом мы не стремимся ни к глобальному доминированию, ни к экспансии какой-то, ни к конфронтации с кем бы то ни было» [12].

С нашей точки зрения, в настоящее время возможно предположить три основных вектора развития политического процесса в глобализирующемся мире, способного оказывать влияние на отечественные модернизационные преобразования:

Первый заключается в реализации модели неолиберальной глобализации с обострением борьбы между странами и регионами за жизненно важные ресурсы, что негативно сказывается на переходе России к инновационному развитию.

Второй вектор развития мирового политического процесса базируется на использовании уже достигнутого превосходства одной или несколькими державами для навязывания собственных условий другим странам, что еще в большей степени обостряет риски и угрозы стабильности и безопасности жизнедеятельности российского общества.

Третий вектор развития политического процесса связан с возможной трансформацией национальных и межгосударственных институтов в сторону глобальной солидарности, реализацией принципов права всех народов на достойную и безопасную жизнь.

Конечно, третий вектор является наиболее желательным. Однако, как показывают события, связанные с «украинским кризисом», процессом воссоединения Крыма с Россией, потребуется еще длительное время для создания механизмов паритетного управления мировым развитием, реализации на практике принципа и права народов на самоопределение.

\section{ПРИМЕЧАНИЕ}

${ }^{1}$ Вопрос о передаче Крымской области из состава РСФСР в состав УССР рассматривался на заседании Президиума ЦК КПСС 25 января 1954 года. Юридически данное решение было оформлено 5 февраля 1954 г. Постановлением Президиума Верховного Совета РСФСР «О передаче Крым- 
ской области из состава РСФСР в состав Украинской ССР». 19 февраля 1954 г. Президиум Верховного Совета СССР принял Указ о передаче Крымской области из состава РСФСР в состав УССР.

\section{СПИСОК ЛИТЕРАТУРЫ}

1. Выступление В.В. Путина на первом заседании нового созыва Государственной Думы Федерального собрания РФ. - Электрон. текстовые дан. - Режим доступа: http://www.kremlin.ru/events/ president/news/53027. - Загл. с экрана.

2. Костяев, С. С. Особенности интеграции и адаптации Крыма в российскую социально-политическую систему / С. С. Костяев, И. В. Юшков // Вестник Финансового университета. Серия «Гуманитарные науки». - 2015. - № 4. - С. 45-52.

3. Кузнецов, И. И. Трансформация форм войны в современной политике: военное и невоенное противостояние на территории Украины 2014 2015 гг. // «Гибридные войны» в хаотизирующемся мире XXI века / под ред. П. А. Цыганкова. - М. : Изд-во Московского университета, 2015. - 384 с.

4. Международные отношения и мировая политика / под ред. П. А. Цыганкова. - М. : Политическая энциклопедия, 2014. -639 с.

5. Межрегиональный форум Общероссийского народного фронта «Форум действий. Крым». Выступление В.В. Путина. - Электрон. текстовые дан. - Режим доступа: http://www.kremlin.ru/events/ president/news/53148 (дата обращения: 26.10.2016). Загл. с экрана.

6. Обращение Президента РФ 18.03.2014 // Бабурин, С. Н. Крым навеки с Россией / С. Н. Бабурин. - М. : Книжный мир, 2014. - 176 с.

7. Постановление Верховной рады Автономной Республики Крым от 17 марта 2014 г. № 1745-6/ 14 «О независимости Крыма». - Электрон. текстовые дан. - Режим доступа: https://ru.wikisource.org/ wiki/Постановление_BP_АРК_от_17.03.2014_ №_1745-6/14 (дата обращения: 25.10.2016). - Загл. с экрана.

8. Пресс-выпуск Левада-Центра от 27.10.2016. Украина и Россия. Опрос проведен 23-26 сентября 2016 года. - Электрон. текстовые дан. - Режим доступа: http://www.levada.ru/2016/10/27/ukraina/. Загл. с экрана.

9. Путин, В. В. Выступление на заседании Международного дискуссионного клуба «Валдай» / В. В. Путин. - Электрон. текстовые дан. - Режим доступа: http://www.kremlin.ru/events/president/ news/53151 (дата обращения: 28.10.2016). - Загл. с экрана.

10. Результаты референдума в Крыму 16 марта 2014: итоговые данные впечатляют. - Электрон. текстовые дан. - Режим доступа: http://vlg-media.ru/ politics/rezultaty-referenduma-v-krymu-16-marta-2014itogovye-danye-vpechatljayut-28049.html (дата обращения: 23.10.2016). - Загл. с экрана.

11. Современная российская политика / под общ. ред. В. И. Коваленко. - М. : Изд-во Моск. ун-та, 2013. $-472 \mathrm{c}$.

12. Стариков, Н. Россия. Крым. История / Н. Стариков, Д. Беляев. - СПб. : Питер, 2016. - 256 с.

13. Restrictions for Crimea and Sevastopol. Electronic text data. - Mode of access: http://europa. eu/newsroom/highlights/special-coverage/eu_ sanctions/index_en.htm (date of access: 03.05.2016).Title from screen.

\section{REFERENCES}

1. Vystuplenie V.V. Putina na pervom zasedanii novogo sozyva Gosudarstvennoy Dumy Federalnogo sobraniya $R F$ [Speech by V.V. Putin at the Opening Session of the New Convocation of the State Duma of the Federal Assembly of the Russian Federation]. Available at: http:// www.kremlin.ru/events/president/news/53027.

2. Kostyaev S.S., Yushkov I.V. Osobennosti integratsii i adaptatsii Kryma v rossiyskuyu sotsialnopoliticheskuyu sistemu [Features of Integration and Adaptation of the Crimea to the Russian Socio-Political System]. Vestnik Finansovogo universiteta. Seriya “Gumanitarnye nauki”, 2015, no. 4, pp. 45-52.

3. Kuznetsov I.I. Transformatsiya form voyny v sovremennoy politike: voennoe i nevoennoe protivostoyanie na territorii Ukrainy 2014-2015 gg. [Transformation of War Forms in Modern Politics: Military and Non-Military Confrontation in Ukraine in 2014-2015]. Tsygankov P.A., ed. "Gibridnye voyny" $v$ khaotiziruyushchemsya mire XXI veka ["Hybrid Wars" in the Randomized World of the 21 st Century]. Moscow, Izd-vo Moskovskogo universiteta, 2015.384 p.

4. Tsygankov P.A., ed. Mezhdunarodnye otnosheniya i mirovaya politika [International Relations and World Politics]. Moscow, Politicheskaya entsiklopediya Publ., 2014. 639 p.

5. Mezhregionalnyy forum Obshcherossiyskogo narodnogo fronta "Forum deystviy. Krym". Vystuplenie V.V. Putina [Interregional Forum of the Popular Front "Forum for Action. Crimea". Speech by V.V. Putin]. Available at: http://www.kremlin.ru/events/ president/news/53148. (accessed October 26, 2016).

6. Obrashchenie Prezidenta RF 18.03.2014 [Message by President of the Russian Federation of March 18, 2014]. Baburin S.N. Krym naveki s Rossiey [Crimea Forever with Russia]. Moscow, Knizhnyy mir Publ., 2014. 176 p.

7. Postanovlenie Verkhovnoy Rady Avtonomnoy Respubliki Krym ot 17 marta 2014 g. № 1745-6/14 
“O nezavisimosti Kryma” [Resolution of the Verkhovna Rada of the Autonomous Republic of Crimea of March 17, 2014 no. 1745-6/14 "On Independence of the Crimea"]. Available at: https://ru.wikisource.org/wiki/ Postanovlenie_VR_ARK_ot_17.03.2014_№_1745-6/14. (accessed October 25, 2016).

8. Press-vypusk Levada-Tsentra ot 27.10.2016. Ukraina i Rossiya. Opros proveden 23-26 sentyabrya 2016 goda [Press Release of the Levada Center of October 27, 2016. Ukraine and Russia. The Survey Was Conducted on September 23-26, 2016]. Available at: http://www.levada.ru/2016/10/27/ukraina.

9. Putin V.V. Vystuplenie na zasedanii Mezhdunarodnogo diskussionnogo kluba "Valday" [Speech at the Meeting of the Valdai International Discussion Club]. Available at: http://www.kremlin.ru/ events/president/news/53151. (accessed October 28, 2016).
10. Rezultaty referenduma $v$ Krymu 16 marta 2014: itogovye dannye vpechatlyayut [Results of the Referendum in the Crimea, March 16, 2014: Overall Data Are Impressive]. Available at: http://vlg-media.ru/ politics/rezultaty-referenduma-v-krymu-16-marta-2014itogovye-danye-vpechatljayut-28049.html. (accessed October 23, 2016).

11. Kovalenko V.I., ed. Sovremennaya rossiyskaya politika [Modern Russian Politics]. Moscow, Izd-vo Moskovskogo un-ta, 2013. 472 p.

12. Starikov N., Belyaev D. Rossiya. Krym. Istoriya [Russia. Crimea. History]. Saint Petersburg, Piter Publ., 2016. 256 p.

13. Restrictions for Crimea and Sevastopol. Available at: http://europa.eu/newsroom/highlights/ special-coverage/eu_sanctions/index_en.htm. (accessed May 3, 2016).

\section{Information About the Authors}

Ekaterina G. Kirsanova, Candidate of Sciences (Politics), Assistant, Department of Russian Politics, Lomonosov Moscow State University, Prosp. Lomonosovskiy, 27, bld. 4, 119991 Moscow, Russian Federation, e-kirsanova@mail.ru.

Sergey A. Pankratov, Doctor of Sciences (Politics), Professor, Head of Department of International Relations, Political Science and Area Studies, Volgograd State University, Prosp. Universitetsky, 100, 400062 Volgograd, Russian Federation, polit@volsu.ru.

\section{Информация об авторах}

Екатерина Геннадьевна Кирсанова, кандидат политических наук, ассистент кафедры российской политики, Московский государственный университет им. М.В. Ломоносова, просп. Ломоносовский, 27, корп. 4, 119991 г. Москва, Российская Федерация, e-kirsanova@mail.ru.

Сергей Анатольевич Панкратов, доктор политических наук, профессор, заведующий кафедрой международных отношений, политологии и регионоведения, Волгоградский государственный университет, просп. Университетский, 100, 400062 г. Волгоград, Российская Федерация, polit@volsu.ru. 